\title{
Alteridades CORPORAIS
}

Carlos Bento

UNIPAC

\begin{abstract}
RES U M O
O texto trata da questão das alteridades corporais, refletindo sobre a condição de corpos que não se enquadram no padrão socialmente imposto, como o de travestis e transexuais. Para tanto, são utilizados o conto "Dia dos namorados", de Rubem Fonseca, e as teorias de Judith Butler.
\end{abstract}

\section{PALAVRAS - CHAVE}

Alteridades corporais. Corpo. Judith Butler.

Em seu pequeno conto "Dia dos namorados", Rubem Fonseca narra a reação do banqueiro mineiro J. J. Santos ao descobrir que sua acompanhante era um travesti. A garota, que disse se chamar Viveca e ter dezesseis anos de idade, fora abordada no calçadão no Rio de Janeiro e levada para a suíte presidencial de um hotel da cidade. Ao descobrir que se tratava de um travesti, "J. J. Santos deu um salto da cama". ${ }^{1}$ A descrição feita por Fonseca mostra a indignação do banqueiro: "Seu pe-pederasta sem ve-vergonha, disse J. J. Apanhou suas roupas e correu para o banheiro, onde se vestiu apressado." A narrativa, a partir desse ponto, se concentra nos desdobramentos daquele encontro que termina em uma delegacia, com Viveca presa e acusada de roubo.

A reação de J. J. Santos diante da descoberta da genitália masculina no corpo de Viveca mostra a presença na literatura de um tipo de alteridade que ocupa um espaço de marginalidade extrema, a respeito do qual ainda se teorizou muito pouco. Enquanto forma de arte e expressão que se relaciona estreitamente com a realidade social, o discurso literário abriga personagens que exibem corpos que desafiam os padrões socialmente legitimados. É fato que os estudos de gênero, nas últimas décadas, avançaram muito e produziram um vultoso corpo de obras que refletem acerca da problemática em torno da padronização dos desejos, das subjetividades, e do gênero. No entanto, tais estudos se debruçam, de uma maneira geral, sobre o que perpassa o corpo, sem refletir a respeito das diversas configurações que ele apresenta, especialmente quando é modificado, como no caso dos travestis e transexuais. Os estudos de gênero, na maioria das vezes, teorizam os corpos masculino e feminino e as relações que eles estabelecem entre si, bem como a relação entre o corpo - especialmente pelo seu caráter sexuado -

\footnotetext{
${ }^{1}$ FONSECA. Dia dos namorados, p. 130.

${ }^{2}$ FONSECA. Dia dos namorados, p. 130.
} 
e o gênero. Este texto utiliza o conto de Rubem Fonseca para, amparado principalmente pelo trabalho de Judith Butler, refletir sobre alteridades corporais.

O corpo, ao longo da história humana, se tornou o marcador de identidade mais sólido e, em geral, fixo. Portador dos caracteres sexuais, exibindo a genitália que define a polarização da sexualidade sancionada, o corpo tornou-se o fator determinante do gênero, a ele subordinado. A presença do sexo biológico sempre foi invocada como prova cabal e irrefutável da necessidade de normalização da prática sexual, bem como das diversas práticas sociais permitidas e atribuídas aos homens e às mulheres. Afinal, se os corpos moldados pela natureza exibiam apenas a dupla configuração masculina e feminina, não parecia, para essa linha de argumentação, cabível permitir um número maior de práticas sexuais. Se a prática sexual exigia a presença de dois corpos, era fácil sustentar que a diferença de genitais serviria a um propósito de complementação, o que garantiria a defesa da prática exclusivamente heterossexual. Mesmo quando os estudos de gênero concluíram que sexo e gênero não são uma única coisa e nem estão necessariamente relacionados de forma interdependente, o corpo se manteve como um índice incômodo de um limite que parecia não poder ser superado. Pensar o gênero como uma abstração que atua sobre a concretude da existência corporal se manteve por um longo período como um esforço teórico grande e, para muitos, pouco convincente.

A resposta para essa questão veio com a publicação do livro Problemas de gênero, de Judith Butler. Nele, a autora afirma que a sujeição às normas de gênero cria a fantasia de um corpo que existe para ser subjugado. Desta forma, Butler mostra que o corpo também é uma construção social. Isto porque, embora sua realidade física, material, não possa ser negada, sem a inscrição social ele não é mais que uma massa biológica. Inserido no contexto social e na cultura, o corpo se torna um fato normatizado e coagido como o gênero. Além disso, é preciso reconhecer que a estabilidade e a fixidez do corpo são fantasias discursivas, usadas como estratégia para sustentar as normas coercitivas impostas pelo controle social. Mesmo se forem desconsideradas as diferenças que são próprias da individualidade humana e que tornam os cruzamentos de subjetividades únicos, a existência de travestis e transexuais, a possibilidade de interferir no corpo e mesmo trocar a genitália por meio de procedimentos cirúrgicos são a afirmação da necessidade de se questionar a supremacia do corpo. Em Butler, essa necessidade se expressa no questionamento de todas as categorias envolvidas na discussão - sexo, gênero, heterossexualidade, homossexualidade - afirmando que todas são, de alguma forma, construções. Ela afirma que "as categorias do sexo verdadeiro, do gênero distinto e da sexualidade específica têm constituído o ponto de referência estável de grande parte da teoria e da política feministas". ${ }^{3}$ Ou seja, mesmo movimentos como o feminista, que precisam questionar o caráter natural, essencial e imutável das categorias de sexo e gênero não o fazem de modo radical. Seu questionamento se efetua de uma maneira que resguarda e mantém a naturalidade e a fixidez de alguns conceitos. E exatamente esses conceitos que permanecem fixos, aceitos como naturais, como essenciais ou como normas, ganham importância fundamental para o movimento feminista, uma vez que

${ }^{3}$ BUTLER. Problemas de gênero, p. 185. 
"esses construtos de identidade servem como pontos de partida epistemológicos a partir dos quais emerge a teoria e a política é formulada". ${ }^{4}$ Portanto, pode-se dizer que é a partir do que se mantém como natural, essencial, que o feminismo se funda, sendo construído dentro de uma lógica dupla, ao mesmo tempo negando e reconhecendo a existência de naturalidade, de essencialidade, nas relações sexo/gênero. Isso porque, "no caso do feminismo, a política é ostensivamente formulada para expressar os interesses, as perspectivas das 'mulheres'". ${ }^{5}$ Com isso, o feminismo pressupõe uma idéia unitária e essencialista de mulher, o que leva Butler a questionar:

Mas há uma forma política das "mulheres", por assim dizer, que preceda e prefigure a elaboração política de seus interesses e do ponto de vista epistemológico? Como essa identidade é modelada? Tratar-se-á de uma modelagem política, que toma as próprias fronteiras e a morfologia do corpo sexuado como base, superfície ou lugar da inscrição cultural? O que circunscreve esse lugar como "o corpo feminino"? É "o corpo" ou "o corpo sexuado" a base sólida sobre a qual operam o gênero e os sistemas da sexualidade compulsória? Ou será que "o corpo" em si é modelado por forças políticas com interesses estratégicos em mantê-lo limitado e constituído pelos marcadores sexuais? ${ }^{6}$

Nesse ponto, Butler atinge o cerne da questão, batendo contra a última fronteira na discussão a respeito do gênero. Ela começa a questionar até que ponto o próprio corpo, apesar de sua materialidade inegável, não é também constituído por processos sociais que o significam e, portanto, o determinam, o constroem. Esse questionamento atinge a base da constituição da teoria e da política feministas, uma vez que estas se baseavam na existência inquestionável de uma entidade política a que se chamava mulher. Tal entidade política era assegurada pela fixidez de uma definição sólida e inquestionável porque se assentava sobre a realidade inegável do corpo. Ora, a forma corporal, ou antes, a forma de um corpo sexuado, que traz em si, ostensivamente, caracteres sexuais que dividem os seres humanos em dois grupos, parecia, até então, estar fora do alcance de qualquer questionamento. Portanto, qualquer argumentação que se propusesse a atacar a hierarquização social baseada no gênero teria que se conformar com o limite da morfologia corporal. Era, assim, impossível alegar igualdade entre homens e mulheres, uma vez que a existência da diferença é óbvia. O grande trunfo de Butler no desenvolvimento de Problemas de gênero foi ignorar, não reconhecer essa alegada obviedade. Para ela, se o corpo é percebido como sendo fixo e o gênero pode ser entendido como construção, a mesma lógica pode ser invertida, resultando em que tanto o sexo quanto o gênero devem ser vistos como construções. A afirmação de que o corpo é significado socialmente abre caminho para se pensar o gênero e a sexualidade livres das amarras da polaridade macho/fêmea. No entanto, sugere que a sociedade, como agente que define o que é o corpo, fixa os limites da aceitabilidade ou não do próprio corpo. Assim, cria o lugar da alteridade marginalizada, que abriga qualquer forma corporal não sancionada. Nesse sentido, Viveca serve como exemplo e como metáfora para se pensar a existência do corpo como definidor de alteridade.

${ }^{4}$ BUTLER. Problemas de gênero, p. 185.

${ }^{5}$ BUTLER. Problemas de gênero, p. 185.

${ }^{6}$ BUTLER. Problemas de gênero, p. 185. 
A reação de J. J. Santos ao se deparar com uma alteridade tão perturbadora no contexto social machista e conservador que impera nos centros urbanos brasileiros mesmo nos maiores e mais presumidamente permissivos, como o Rio de Janeiro - está longe de ser uma novidade na literatura ou em outras formas de expressão, como o cinema. Basta lembrar de casos paradigmáticos como o representado no filme Traídos pelo desejo, dirigido por Neil Jordan, em que a descoberta do sexo biológico provoca o vômito da personagem masculina que cortejava o travesti. No entanto, o conto de Fonseca apresenta alguns aspectos interessantes. Em primeiro lugar, o banqueiro, casado, não se intimidou com o fato de procurar os serviços de prostituição e nem com a descoberta de que Viveca era menor de idade, fato revelado no momento da abordagem, ainda no calçadão. Embora ela seja descrita como uma garota de notável beleza e feminilidade, a repulsa se dá pelo encontro com um corpo que desmentia a identidade de gênero presumida inicialmente. Há um choque no encontro com uma forma de identidade diferente e marginalizada. Afinal, o corpo do travesti, no caso, resumia não apenas a repulsa à homossexualidade, mas ao corpo que é modificado e que ostenta um sexo escondido, disfarçado, negado até o momento da nudez completa. Um corpo que, rejeitando o padrão polarizado aceito socialmente, se torna abjeto, grotesco. Na narrativa de Rubem Fonseca, a reação do banqueiro não parece ser a afirmação do desejo heterossexual, mas a repulsa pela homossexualidade. Sua raiva é expressa em tom acusatório, chamando Viveca de "pederasta sem vergonha". Nesse caso, o travestismo se torna um agravante, uma forma de subjetividade mais abjeta que a homossexualidade, pois é capaz de esconder o sexo biológico, descoberto somente no momento da nudez completa. Essa característica enganadora - muitas vezes fator de fascínio e de sedução - pode ser entendida como uma justificativa para o susto de J. J. Santos, sancionando sua indignação. No entanto, Viveca retruca: "Você sabia o que eu era, me trouxe aqui sabendo de tudo, e agora me despreza como se eu fosse lixo." ${ }^{7}$ Esta fala denuncia que a indignação e a raiva do banqueiro são atitudes reveladoras do cinismo social. Pois nas grandes cidades, as áreas de prostituição costumam ser demarcadas, e sabe-se onde ficam as mulheres e os travestis. Além disso, a prostituição é uma prática condenada socialmente, independente do tipo, do sexo e do gênero de quem se prostitui. E a prática de sexo com menores de idade é, além de socialmente reprovada, crime. No entanto, o que provoca a raiva e a indignação é a homossexualidade e o travestismo, ficando todo o resto ignorado. Isto mostra como, socialmente, a reprovação e a condição de marginalidade são hierarquizadas. Prostitutas mulheres, mesmo menores de idade, constituem uma transgressão menos grave que a homossexualidade e o travestismo.

A representação do travesti mostra uma das configurações corporais que desafiam a lógica normatizadora social, a qual estabelece rígidos padrões não apenas de comportamento como de morfologia corporal. Este tema foi tratado por Butler em ensaios reunidos no livro Undoing Gender. Nele, a autora afirma que a naturalização do gênero elege formas ideais não apenas para as relações, mas também para os corpos, que se tornam aceitos ou proibidos, gerando a marginalização de sujeitos que se colocam como

${ }^{7}$ FONSECA. Dia dos namorados, p. 131. 
travestis, ou transexuais, ou qualquer outro tipo de forma ou apresentação corporal classificada como desviante. Assim, ao se questionar a norma, abre-se a possibilidade de não se poder mais falar em desvio, uma vez que este, óbvio, só pode se constituir em relação àquela. Esse tipo de questionamento está na base do que constitui a teoria queer, razão pela qual Butler é considerada, ao lado de Eve Sedgwick, uma de suas fundadoras. A teoria queer se propõe a incluir as diversas formas de subjetividades de gênero que não se enquadram no padrão socialmente aceito. $O$ caráter inclusivo se deve ao fato de que, nos últimos anos, gay e lésbica passaram a designar tipos específicos de homossexualidade masculina e feminina, respectivamente. Um grande número de sujeitos permanecia estranho, queer, marginais em relação a essas duas categorias. Forçando os limites da teoria queer, mais recentemente Butler tem concentrado sua escrita em torno do tema da morfologia corporal, de como a forma do corpo é normatizada e, em caso de não conformidade com a norma, se torna justificativa para a exclusão do sujeito, que é condenado a uma vida insuportável ou mesmo à morte social, e até literal.

Claro que a possibilidade de exclusão social, de violência e até de morte, não ameaça apenas os sujeitos que têm uma forma corporal que desafia a norma socialmente consagrada. Essas são ameaças feitas a todos que não estão conformados aos padrões estabelecidos como apropriados socialmente quanto ao gênero e à sexualidade. É preciso pensar o corpo não apenas como a massa biológica, mas como um amálgama que envolve as práticas e contextos em que ele se insere e com que interage. Nesse sentido, pode-se dizer que o corpo de alguém que pratica a homossexualidade não se conforma ao padrão socialmente aceito, mesmo que não tenha sofrido nenhum tipo de intervenção. Isto porque, ao estar presente e mediar um comportamento proscrito, o corpo também se torna abjeto, e não apenas o ato. Seguindo a mesma lógica, pode-se considerar a aversão ao homossexual afeminado, fato comum mesmo entre os homossexuais, uma forma de rejeição de um tipo de não-conformidade do corpo. Em um pequeno artigo intitulado "How to bring your kids up gay: the war on effeminate boys", Sedgwick reflete sobre a maneira hostil com que os movimentos gays encaram os homens afeminados. Para ela, isso se deve à idéia de que para se convencer de que um homem, como tal, possa desejar outro homem, e que uma mulher feminina possa desejar outra, ou seja, "a necessidade indispensável de tornar essas asserções subversivas poderosas parece, talvez, requerer uma relativa desenfatização das ligações entre gays adultos e crianças não conformadas ao gênero". ${ }^{8}$ Por isso há a rejeição dos afeminados. Nisso se rejeita seus corpos, num sentido performático - tanto quanto no caso da rejeição do corpo do homossexual não-afeminado, comentado anteriormente -, pois o corpo está misturado com a performance, com sua presentificação.

Como exemplos da marginalização imposta aos indivíduos que não se conformam ao padrão estabelecido como norma, Butler e outros teóricos escrevem repetidamente sobre a política implementada pelo exército dos EUA, conhecida como "don't ask, don't tell", bem como a respeito do assassinato do jovem Matthew Shepard, um universitário

\footnotetext{
${ }^{8}$ SEDGWICK. How to bring your kids up gay, p. 157: "the indispensable need to make these powerful, subversive assertions has seemed, perhaps, to require a relative deemphasis of the links between gay adults and gender-nonconforming children”. (Tradução nossa).
} 
homossexual que foi espancado e amarrado a uma cerca de arame farpado, ainda vivo e consciente, por outros jovens, por causa de sua homossexualidade. Tanto no caso da política implementada pelo pentágono quanto no caso de violência extremada que causa a morte literal, o simples fato de uma identidade homossexual, apesar da presença de um corpo que, se pensado apenas como forma biológica, não se mostra como "desviante", é causa da exclusão do sujeito.

Considerando casos como esses, da política homofóbica implementada pelo pentágono e de homicídios como o que vitimou Shepard, Butler afirma, em relação às ameaças que rondam a existência dos corpos, dos desejos, do gênero dos indivíduos que não estão em conformidade com o que se convencionou chamar de norma social, especialmente os homossexuais: "somos, como uma comunidade, sujeitos à violência, mesmo se alguns de nós individualmente não o tenham sido". ${ }^{9}$ Dessa forma, claro, um fato trágico como a morte de Matthew Shepard é uma violência contra toda a comunidade homossexual, uma vez que sua morte foi uma agressão não apenas a ele, mas contra o "desvio" que ele representava. Butler continua seus argumentos nos seguintes termos: "isto significa que nós somos constituídos politicamente, em parte, em virtude da vulnerabilidade social de nossos corpos; nós somos constituídos como campos de desejo e de vulnerabilidade física, ao mesmo tempo publicamente visíveis e vulneráveis". ${ }^{10}$ Assim, o corpo se coloca numa posição dupla, ao mesmo tempo garantindo a vida do indivíduo e a ameaçando. Isso leva Butler a concluir que "o corpo implica mortalidade, vulnerabilidade, agência: a pele e a carne expõem-nos ao olhar dos outros, mas também ao toque e à violência" ${ }^{11}$ Com isso, por meio da materialidade estreitamente normatizada do corpo, é preciso reconhecer que "na medida em que o desejo está implicado nas normas sociais, ele é determinado pela questão do poder e pelo problema de quem se qualifica como reconhecidamente humano e quem não se qualifica como tal". ${ }^{12}$ De acordo com esse raciocínio, homossexuais, transexuais, hermafroditas, travestis etc., não se qualificam como "humanos", nem como cidadãos, pelo menos não na totalidade do que esses termos podem significar. Essa falta de reconhecimento se consolida de diversas maneiras, como a imposição de dificuldades para que transexuais, mesmo operada/ o(s) possam, mudar os documentos de identidade, ou a recusa de direitos a casais do mesmo sexo. Esses dois exemplos mostram como se promove a exclusão, impondo uma forma de violência que se amplia exponencialmente, pois persegue os indivíduos por longos períodos ou pela vida toda, expondo-os constantemente ao confronto e ao repúdio social. No caso do conto de Rubem Fonseca, fica claro que a condição de menor de idade não é relevante no momento da autuação de Viveca por roubo, na delegacia. Em

\footnotetext{
${ }^{9}$ BUTLER. Undoing Gender, p. 18.

${ }^{10}$ BUTLER. Undoing Gender, p. 18: "And this means that we are constituted politically in part by virtue of the social vulnerability of our bodies; we are constituted as fields of desire and physical vulnerability, at once publicly assertive and vulnerable." (Tradução nossa).

${ }^{11}$ BUTLER. Undoing Gender, p. 21: "the body implies mortality, vulnerability, agency: the skin and the flesh expose us to the gaze of others but also to touch and to violence". (Tradução nossa).

${ }^{12}$ BUTLER. Undoing Gender, p. 2: "To the extent that desire is implicated in social norms, it is bound up with the question of power and with the problem of who qualifies as the recognizably human and who does not." (Tradução nossa).
} 
nenhum momento o texto cita alguém questionando a situação em que o roubo aconteceu, ou levando em conta o fato da contratação de alguém menor de idade para prestar serviços sexuais, o que constitui crime. Pode-se inferir que a condição de travesti naturaliza a prostituição, bem como exclui Viveca da inocência e da fragilidade que se presumem como características de quem é menor de idade, e que é o que justifica sua proteção especial perante a lei. Considerando o contexto social brasileiro, se a narrativa continuasse, talvez fosse possível ler alguma descrição de Viveca sofrendo abusos na delegacia, ou mesmo prestando favores sexuais para se livrar da cadeia.

Voltando às considerações anteriores, as conseqüências da não-conformidade aos padrões de normalização social podem ser muito mais literalmente violentas, claro, provocando internações, aprisionamentos, ataques corporais e mesmo assassinatos. Assim, a partir da idéia de que a existência do indivíduo está condicionada ao reconhecimento do outro, Butler afirma:

Eu posso perceber que, sem reconhecimento, eu não posso viver. Mas eu posso também perceber que os termos pelos quais eu sou reconhecido tornam a vida impossível de se viver. Este é o ponto de onde a crítica emerge, compreendida como uma interrogação dos termos pelos quais a vida é forçada para abrir a possibilidade de diferentes modos de vivências; em outras palavras, não celebrar a diferença como tal, mas estabelecer condições mais inclusivas para abrigar e manter a vida que resiste a modelos de assimilação. ${ }^{13}$

Assim, a forma de reconhecimento garantida aos sujeitos pode funcionar mais no sentido de apagar ou desmerecer sua existência do que de garantir o direito à vida. $\mathrm{Ou}$ seja, algumas formas de reconhecimento garantem a existência do sujeito, mas de uma maneira que sugere que tal sujeito deve deixar de existir, que tal existência deve ser atacada e apagada, por meio de atos de violência diversos. Na citação acima, Butler aproxima a prática acadêmica, a atividade crítica, da militância, do que alguns de seus críticos consideram como realidade. Pois ela define o papel da crítica como sendo o de um agente de interferência prática, que se preocupa com a criação e ampliação das condições de vida dos sujeitos "diferentes". Dentro dessa lógica, pensando nos vários movimentos que lidam com sujeitos que não se enquadram dentro dos padrões socialmente definidos, como a teoria queer, Butler afirma que sua tarefa é a de distinguir, entre as normas e convenções sociais, aquelas que permitem que os seres humanos vivam e aquelas que tornam a vida insuportável. Sua argumentação é de que as normas podem funcionar de maneiras diferentes para os diversos grupos sociais. Sendo assim, há a necessidade de se parar de impor para todos normas que são suportáveis para alguns, ou proibir para todos coisas que são insuportáveis para determinados grupos. ${ }^{14}$ Dessa maneira, Butler afirma que o papel da crítica de gênero deve estar centrado na

\footnotetext{
${ }^{13}$ BUTLER. Undoing Gender, p. 4: "I may feel that without some recognizability I cannot live. But I may also feel that the terms by which I am recognized make life unlivable. This is the juncture from which critique emerges, where critique is understood as an interrogation of the terms by which life is constrained in order to open up the possibility of different modes of living; in other words, not to celebrate difference as such but to establish more inclusive conditions for sheltering and maintaining life that resists models of assimilation." (Tradução nossa).
}

${ }^{14}$ BUTLER. Undoing Gender, p. 8. 
identificação e no ataque às normas que governam as relações sociais. Existe, ainda, a sugestão de que a crítica atua separada da vida cotidiana, uma vez que há a afirmação de que é nesse aspecto que deve se concentrar o foco. Afinal, a existência de normas que determinam o que é aceitável ou não quanto ao gênero tem efeitos que não deveriam ser admitidos, tolerados, pois atentam contra o direito primário da vida. A tolerância em relação às normas, nesse caso, só pode existir na medida em que se entende que elas não podem ser aplicadas universalmente, pois esse procedimento, inevitavelmente, deixa todo um conjunto de indivíduos ou grupos de indivíduos em condição de exclusão. Como à crítica cabe o papel de confrontar essas normas, Butler empreende em seu trabalho, desde Problemas de gênero, um esforço para desconstruir a própria noção de gênero, em seu sentido de instância ao mesmo tempo normatizada e normatizadora. Apontando para o processo de construção de seu próprio pensamento, ela afirma que suas idéias sobre gênero têm sido refinadas ao longo do tempo. ${ }^{15}$ Esse refinamento da concepção de gênero esboçada em seu livro seminal ocorre em torno de muitas noções, chegando à reflexão acerca da morfologia corporal.

Tudo isso mostra como o pensamento sobre as formas de alteridade, especificamente aqui, as alteridades corporais, aborda um tema cada vez mais presente no contexto social brasileiro. O conto de Rubem Fonseca é um exemplo de como a literatura se presta a representar a situação social de sujeitos que não se enquadram no pequeno grupo chamado de maioria. Com esse tipo de representação, a literatura se coloca o desafio de, em alguma medida, ao menos denunciar a existência de indivíduos que constituem minorias entre grupos considerados minoritários. A partir da imagem de Viveca é possível especular que algumas formas de subjetividade são tão especificamente minoritárias, que jamais estarão em condição de pleitear, sozinhas, o pleno reconhecimento social. Afinal, parece pouco provável que formas corporais tão radicalmente subversivas, como no caso de travestis e transexuais, possam se tornar numerosas a ponto de constituir comunidades capazes de se impor no jogo de negociações de poder a que se dá o nome de cultura.

O corpo de Viveca ganha uma dimensão ainda mais dramática no conto, pois ela corta o próprio braço, repetidas vezes, com uma gilete, quando o banqueiro a acusa de ter roubado o dinheiro que estaria em sua carteira. Os cortes, cobrindo os braços de sangue, eram uma estratégia de chantagem. Viveca exige dinheiro para não se matar e causar transtornos para o acompanhante. Na delegacia, fica claro que se tratava de uma estratégia utilizada com freqüência, pois "antes de trancarem Viveca no xadrez, viram que ele tinha uma porção de marcas antigas nos dois braços". ${ }^{16}$ Assim, com apenas dezesseis anos, Viveca tinha sua existência garantida por um corpo alterado pelos procedimentos que garantem a condição de travesti e marcado por diversos cortes de gilete. Uma estratégia que, se no conto é interpretada como forma de chantagem, certamente pode ser lida como metáfora de uma forma de registro das agressões que sofria socialmente pela condição de alteridade a que estava submetida.

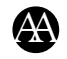

\footnotetext{
${ }^{15}$ BUTLER. Gender Trouble, p. xxv.

${ }^{16}$ FONSECA. Dia dos namorados, p. 135.
} 


\section{A B S TR A C T}

This paper deals with the issue of bodily alterities, thinking about the condition of bodies that do not fit the socially imposed standards, such as those of transvestites and transsexuals. For this purpose, it uses the short story entitled "Dia dos namorados", by Rubem Fonseca, and the theories by Judith Butler.

\section{KEYWORDS}

Bodily alterities. Body. Judith Butler.

\section{REFERÊNCIAS}

BUTLER, Judith. Gender Trouble: feminism and the subversion of identity. New York; London: Routledge, 1999.

BUTLER, Judith. Problemas de gênero: feminismo e subversão da identidade. Trad. Renato Aguiar. Rio de Janeiro: Civilização Brasileira, 2003.

BUTLER, Judith. Undoing Gender. New York; London: Routledge, 2004.

FONSECA, Rubem. Dia dos namorados. In: RUFFATO, Luiz. Entre nós: contos sobre homossexualidade. Rio de Janeiro: Língua Geral, 2007. p. 125-136.

RUFFATO, Luiz. Entre nós: contos sobre homossexualidade. Rio de Janeiro: Língua Geral, 2007.

SEDGWICK, Eve Kosofsky. Tendencies. Durham: Duke University Press, 1993.

SEDGWICK, Eve Kosofsky. How to bring your kids up gay: the war on effeminate boys. In: . Tendencies. Durham: Duke University Press, 1993. p. 154-164. 